\title{
Season determines timing of first ovulation in rhesus monkeys (Macaca mulatta) housed outdoors
}

\author{
M. E. Wilson and T. P. Gordon \\ Yerkes Regional Primate Research Center, Emory University, Field Station, 2409 Taylor Road, \\ Lawrenceville, GA 30243, USA
}

\begin{abstract}
Summary. In order to determine the relative importance of age and season on the occurrence of first ovulation in rhesus monkeys, the timing of puberty in spring-born females (Group $S, N=13$ ) was compared to that of fall $(N=3)$ and winter-born $(\mathrm{N}=5)$ females (Group W). All females were housed outdoors and were studied from 12 months of age through first ovulation. Menarche occurred at a similar age but significantly earlier in the year for Group W (31.2 \pm 0.7 months; 25 August \pm 19.5 days) than for Group $S$ females $(31 \cdot 2 \pm 0.7$ months; 14 November $\pm 17 \cdot 1$ days). First ovulation, as assessed from twice weekly serum progesterone determinations, occurred exclusively in the fall or winter in a bimodal age distribution for all females. For Group W females, $6 / 8$ ovulated during the 3 rd year at $35.8 \pm 0.7$ months while $2 / 8$ ovulated during the 4 th year at $45 \cdot 3 \pm 0 \cdot 1$ months. In contrast, only $3 / 13$ Group $S$ females ovulated during the $3 \mathrm{rd}$ year and at a significantly younger age of $31.4 \pm 0.4$ months compared to Group W. The remaining Group S females (10/13) ovulated the following autumn at $43.2 \pm 0.2$ months, significantly younger than the later ovulating Group $W$ females. In addition to this pattern of first ovulation, serum concentrations of prolactin varied seasonally, rather than with age, in both groups of females with higher levels in the summer and low levels in the winter. These results suggest that exposure to an outdoor environment restricts the occurrence of first ovulation to the fall or winter in female rhesus monkeys, regardless of season of birth, such that seasonal cues may override the endogenous control of puberty onset. If females enter the months of autumn at a more advanced developmental age relative to menarche, they are more likely to exhibit first ovulation.
\end{abstract}

Keywords: first ovulation; environment; season; prolactin; rhesus monkey

\section{Introduction}

Rhesus monkeys living in outdoor environments are seasonal breeders with ovulations restricted to the fall and winter and births to the spring and summer (van Horn, 1980; Gordon, 1981; Walker $e t$ al., 1984). When spring-born females are raised outdoors first ovulation, but not menarche, is also seasonally restricted (Wilson et al., 1984, 1986). Menarche typically occurs from 27-36 months of age throughout the year while first ovulation for these spring-born females occurs exclusively in the fall at 31 or 43 months of age, with about $20 \%$ of the females exhibiting first ovulation at the earlier age (Wilson et al., 1984, 1986). Spring-born females that experience menarche at an earlier age have an increased probability of exhibiting first ovulation within the perimenarchial breeding season at 31 months of age (Wilson et al., 1986).

Although these results suggest that an outdoor environment may regulate the timing of first ovulation in rhesus monkeys, analyses to date have used only spring-born monkeys and so season and age have been confounded; it is therefore possible that females are maturing at a particular age 
which coincides with a particular season. In a previous analysis of colony birth records, females that were born in the fall and housed outdoors eventually had first parturition, as is typical, in the spring, at a later than normal age and not in the fall as would be expected if age alone were the predominant factor (Wilson et al., 1984). However, as a direct assessment of ovulation was not made, these females may have exhibited an undetected ovulation the previous spring or summer. A better understanding of the role of the environment in the regulation of first ovulation in rhesus monkeys is needed to help identify the factor or factors which initiate and maintain reproductive development.

The present study examined the relative importance of age and season on the timing of first ovulation in rhesus monkeys. The timing of maturational events for spring-born and winter-born females raised outdoors was compared to determine if seasonal changes could override the influence of age, thus restricting first ovulation to the fall months. Furthermore, since prolactin concentrations vary seasonally in spring-born rhesus monkeys before puberty (Wilson et al., 1985), the present study also assessed how developmental changes were modified by season.

\section{Materials and Methods}

\section{Animals}

Two groups of female rhesus monkeys (Macaca mulatta) were used as subjects. Females in Group $\mathrm{S}$ were born in the compound-housed Yerkes Primate Research Center breeding colony (mean $=9$ April, s.e.m. $=12$ days) and raised outdoors from birth. Five of the females were studied from April 1985 to December 1987 concurrently with the winter-born animals described below and the other 8 females were studied from April 1982 to November 1984 . Maturational data for the latter have been previously reported (Wilson et al., 1986) and these animals were included to increase the sample of spring-born females. Mean birth dates were indistinguishable between these 2 subgroups ( 1 April \pm 12 days vs 19 April \pm 11 days; $t_{12}=1.02$ ). All Group $S$ females remained with their mothers until at least 4 months of age.

Females in Group $W$ were born in the fall $(\mathrm{N}=3 ; 8$ October \pm 17 days $)$ or winter $(\mathrm{N}=5 ; 27$ January \pm 7 days $)$ and raised outdoors. Females born during the fall were obtained from timed-breeding programmes (one from the Yerkes Primate Research Center and two from the California Primate Research Center) while females born in the winter were obtained from the Caribbean Primate Research Center in which the middle of the birth season coincides with late February (Rawlins \& Kessler, 1985). All Group W females remained with their mothers until at least 4 months of age and were raised outdoors at the Yerkes Field Station from 6 months of age. The females in Groups $\mathrm{S}$ and $\mathrm{W}$ were therefore exposed to the same environment throughout development.

\section{Procedures}

Animals lived outdoors in mixed-sex social groups containing several adult males and females and juvenile offspring. The outdoor enclosures measured $30 \times 30 \mathrm{~m}$ and had attached indoor quarters as previously described (Walker et al., 1982). Animals were exposed to natural conditions throughout the year except that heat was provided during the inclement winter months. The indoor quarters had windows to the outside and were artificially lit only during periods of daily maintenance. The monkeys were therefore exposed to ambient photoperiod throughout the study.

The study was begun in April when Group S females were 12 months of age and Group W females were 15-18 months of age. Blood samples were collected once weekly until 20 months of age for all females and twice weekly thereafter. Body weights were obtained monthly following an 18 -h overnight fast.

Blood samples were obtained from capture acclimatized, unanaesthetized animals as described previously (Walker et al., 1982). All samples were obtained within $4-5 \mathrm{~h}$ of sunrise. Serum was collected and stored at $-20^{\circ} \mathrm{C}$ until assay. Menstruation was detected by daily visual inspection and by insertion of a cotton-tipped applicator into the vagina at each blood sampling time. Luteal-phase function at first ovulation was assessed from serum progesterone concentrations. Short luteal phases were considered to be those in which serum progesterone remained elevated for $<7$ days and did not exceed $2.0 \mathrm{ng} / \mathrm{ml}$ (Foster, 1977; Wilks et al., 1979).

Serum concentations of progesterone were measured by radioimmunoassay (RIA) using a commercially prepared kit (Diagnostic Products Corp., Los Angeles, CA, USA). At $100 \mu$ l serum, the assay has a sensitivity $(80 \% \mathrm{~B} / \mathrm{Bo})$ of $0.3 \mathrm{ng} / \mathrm{ml}$. Intra- and interassay CVs were $3.1 \%$ and $8.7 \%$, respectively. Serum concentrations of prolactin were quantified by a human prolactin RIA (Wilson et al., 1985). Coefficients of variation were $<10 \%$.

\section{Analyses}

All grouped data were expressed as mean \pm s.e.m. Differences between Groups $\mathrm{S}$ and $\mathrm{W}$ were analysed with $t$ tests for independent samples, and when appropriate, analysis of variance models for repeated measures. Specific 
comparisons between groups across advancing ages or seasons were made with Scheffe post-hoc tests. Linear relationships were evaluated with Pearson product moment correlations. Frequency data were evaluated by $\chi^{2}$ tests. All statistical values at $P<0.05$ were considered significant.

\section{Results}

Exposure to an outdoor environment restricted first ovulation, but not menarche, to the fall months, regardless of season of birth (Fig. la, b). Age at menarche was not significantly different between Groups $S(31.2 \pm 0.7$ months $)$ and $W\left(31.2 \pm 0.7\right.$ months; $\left.t_{19}=0\right)$. Given the differences in birth seasons, menarche occurred significantly earlier in the year for Group W females (25 August \pm 20 days) than in Group S (14 November \pm 17 days; $\left.t_{19}=2 \cdot 86\right)$. The occurrence of menarche ranged from June through November for Group W females and from July through December for Group S females. Comparing the two subgroups of Group S females, those studied previously had menarche at an age $\left(31 \cdot 0 \pm 1 \cdot 1\right.$ months; $\left.t_{11}=0 \cdot 15\right)$ and date $(17$ November \pm 28 days; $t_{11}=0.38$ ) similar to those for the other Group $S$ females (age: $31.6 \pm 0.4$ months; date 11 November $\pm 8 \cdot 1$ days). As can be seen in Fig. 1(a), $90 \%$ of the females (Groups S and W combined) experienced menarche between late spring and late fall. Also, $76 \%$ of the females had menarche between 30 and 33 months (Fig. Ib).

First ovulation for females in Groups $\mathrm{S}$ and $\mathrm{W}$ was restricted to the fall or early winter in a bimodal age distribution (Fig. 2a) and group differences were observed in the percentage of monkeys ovulating early (i.e. during the 3rd year); in the age at first ovulation; and in the date of first ovulation. Significantly more of the Group S females $(10 / 13)$ had first ovulation during the 4th year at $43.2 \pm 0.2$ months than during the 3 rd year (3/13) at $31 \cdot 4 \pm 0.4$ months $\left(\chi^{2}{ }_{1}=7 \cdot 53\right)$. Of the two Group S subgroups, all of the females studied concurrently with Group W ovulated during the 4 th year at a mean age of $43.5 \pm 0.3$ months, indistinguishable from the other Group $S$ females ovulating during that year $(43 \cdot 0 \pm 0 \cdot 2 ; \mathrm{N}=5)$. Group $\mathrm{W}$ females also exhibited first ovulation in a bimodal age distribution and these, too, were restricted to the months of autumn. In contrast to the pattern observed for the Group S females, significantly more Group W females (6/8) showed an early first ovulation at $35 \cdot 8 \pm 0 \cdot 7$ months with the remaining females $(2 / 8)$ ovulating at $45 \cdot 3 \pm 0 \cdot 1$ months $\left(\chi_{1}^{2}=9 \cdot 00\right)$. The number of Group $W$ females which ovulated during their $3 r d$ year $(6 / 8)$ was significantly more than that observed for Group $S$ females $\left(3 / 13 ; \chi^{2}{ }_{1}=7 \cdot 44\right)$. The age at the early first ovulation was significantly greater for Group W than Group S females $\left(t_{7}=3.77\right)$ and these ovulations also occurred significantly earlier in the year for Group W (27 November \pm 6 days) than in the early ovulating Group S females (27 December \pm 7 days; $t_{7}=2 \cdot 69$ ). The remaining Group W females had first ovulation the next fall at a significantly later age than the other Group $S$ females $\left(t_{10}=4 \cdot 26\right)$ but at a similar time of year (30 October \pm 3 days vs 3 November \pm 4 days; $t_{10}=0 \cdot 76$ ). As can be seen in Fig. 2(a), $100 \%$ of the females in both groups combined had first ovulation in the fall or early winter. Furthermore, the correlation between birth date and age at first ovulation (Fig. 2b) was significant for both the early ovulating females $(r=-0.99 ; \mathrm{df}=7)$ and the late-ovulating group $(r=-0.92 ; \mathrm{df}=10)$, suggesting that within any distribution of first ovulations younger females are more likely to have been born in spring or early summer.

Of the 21 females studied, 19 had normal luteal phases at first ovulation as assessed from serum progesterone concentrations. Two females, one in each of Groups $\mathbf{S}$ and W, exhibited a short luteal phase at first ovulation. Both of these females ovulated during their $3 \mathrm{rd}$ year $(30.8$ and 34.0 months, respectively). Furthermore, body weight at first ovulation was significantly related to age $(r=0.58$, $\mathrm{df}=19$ ), with older females being heavier at first ovulation. Weight gain from 12 to 30 months of age was also similar between Group W $(1.74 \pm 0.08 \mathrm{~kg})$ and Group S females $(1.82 \pm 0.06 \mathrm{~kg}$; $\left.t_{19}=0 \cdot 76\right)$.

Serum prolactin concentrations exhibited a distinct seasonal rhythm for Group $\mathrm{S}$ animals, with peak levels in the summer and nadirs in late fall (Fig. 3). A similar rhythm in serum prolactin is 


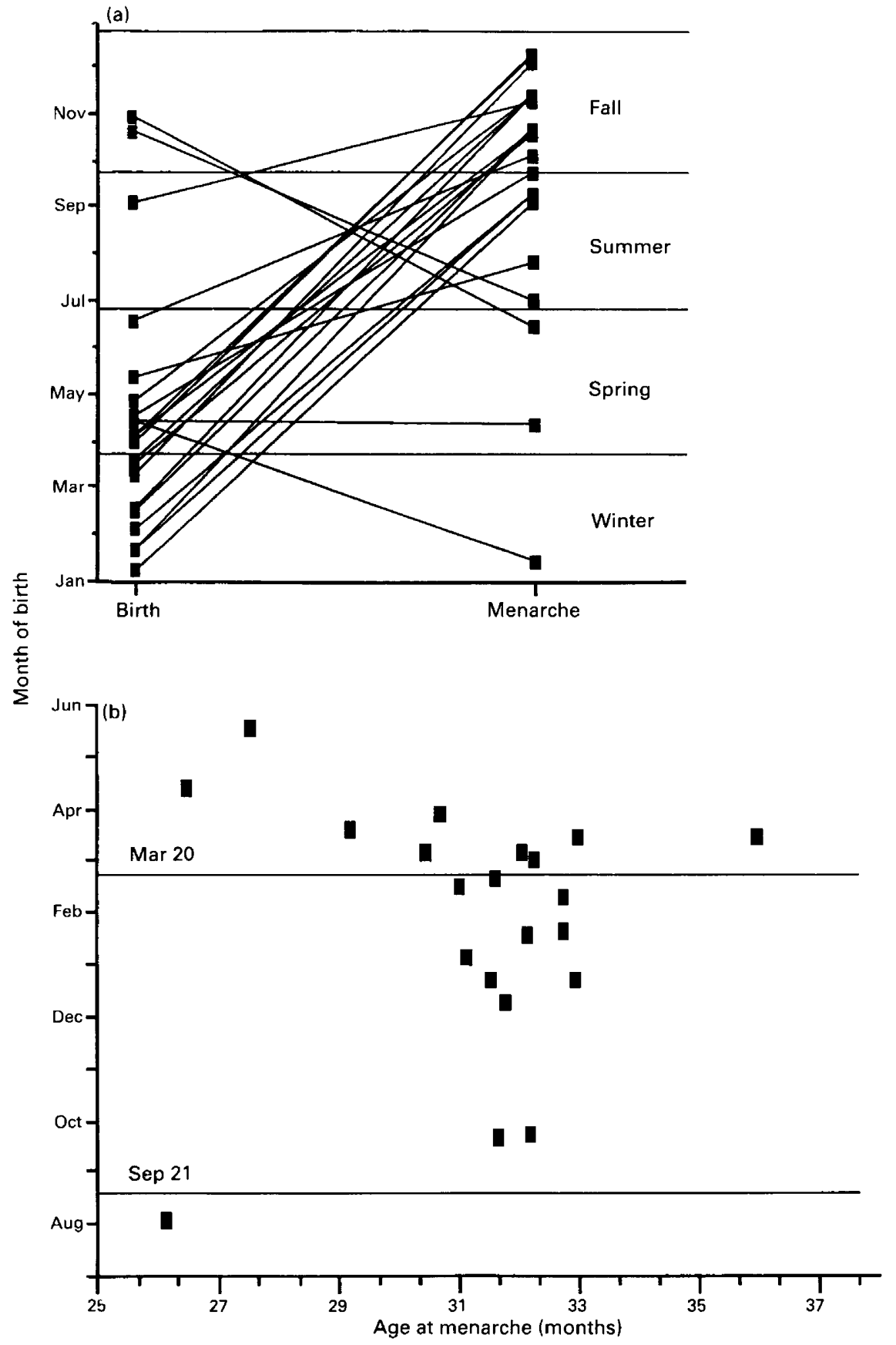

Fig. 1. Relationship between month of birth and month in which menarche occurred (a) and distribution of age at menarche by month of birth (b).

observed for Group W females when data are aligned to months of the year (Fig. 3a) but not age (Fig. 3b). Indeed, by aligning data to age rather than season, serum concentrations of prolactin were elevated for Group W females when concentrations were decreased for Group S animals. 


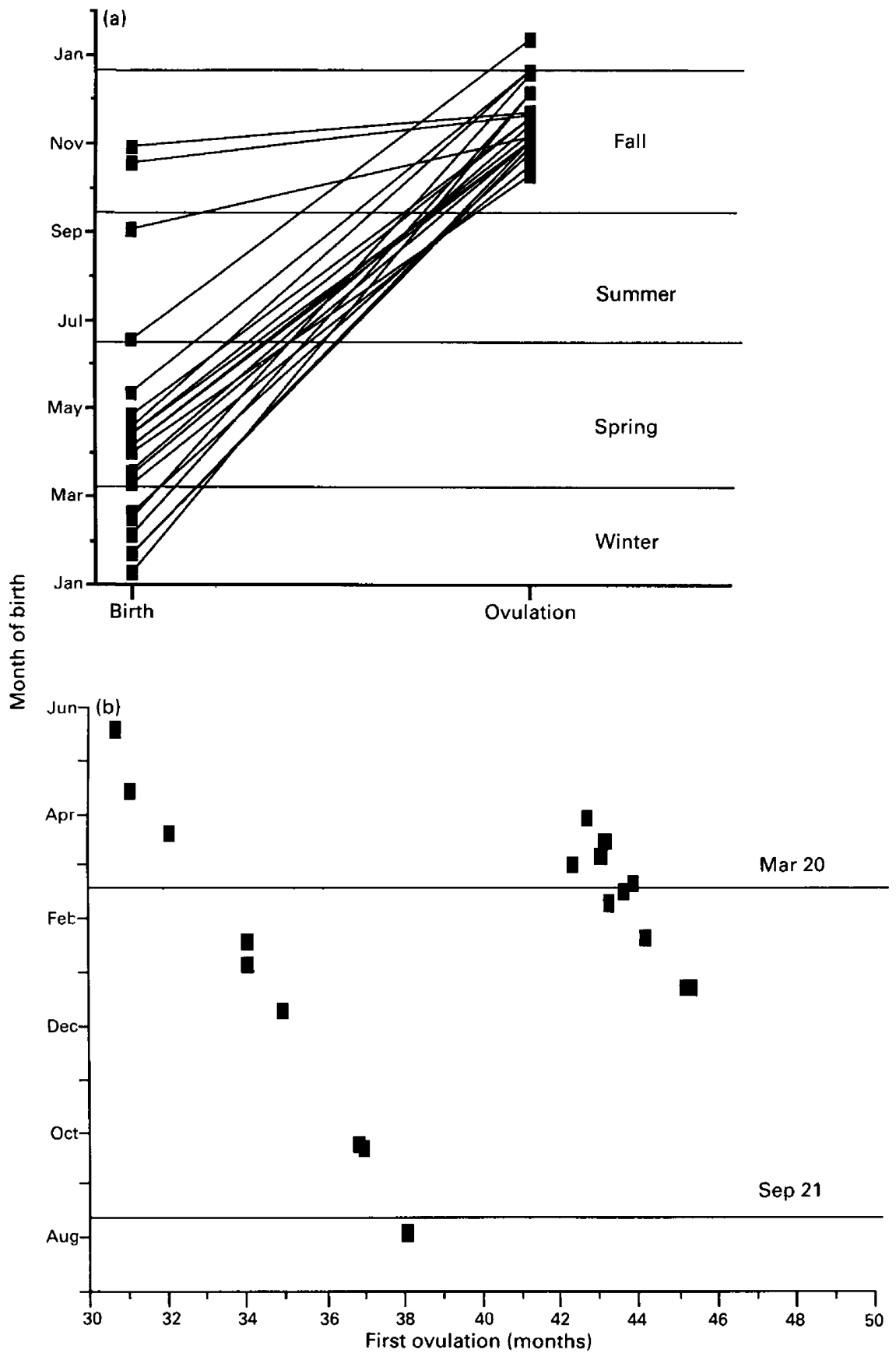

Fig. 2. Relationship between month of birth and month in which first ovulation occurred (a) and distribution of age at first ovulation by month of birth (b).

\section{Discussion}

The results of the present study indicate that animals exposed to a seasonal environment have first ovulation restricted to the fall months regardless of season of birth. All fall- and winter-born females ovulated during autumn and not during the summer as would have been expected if age 

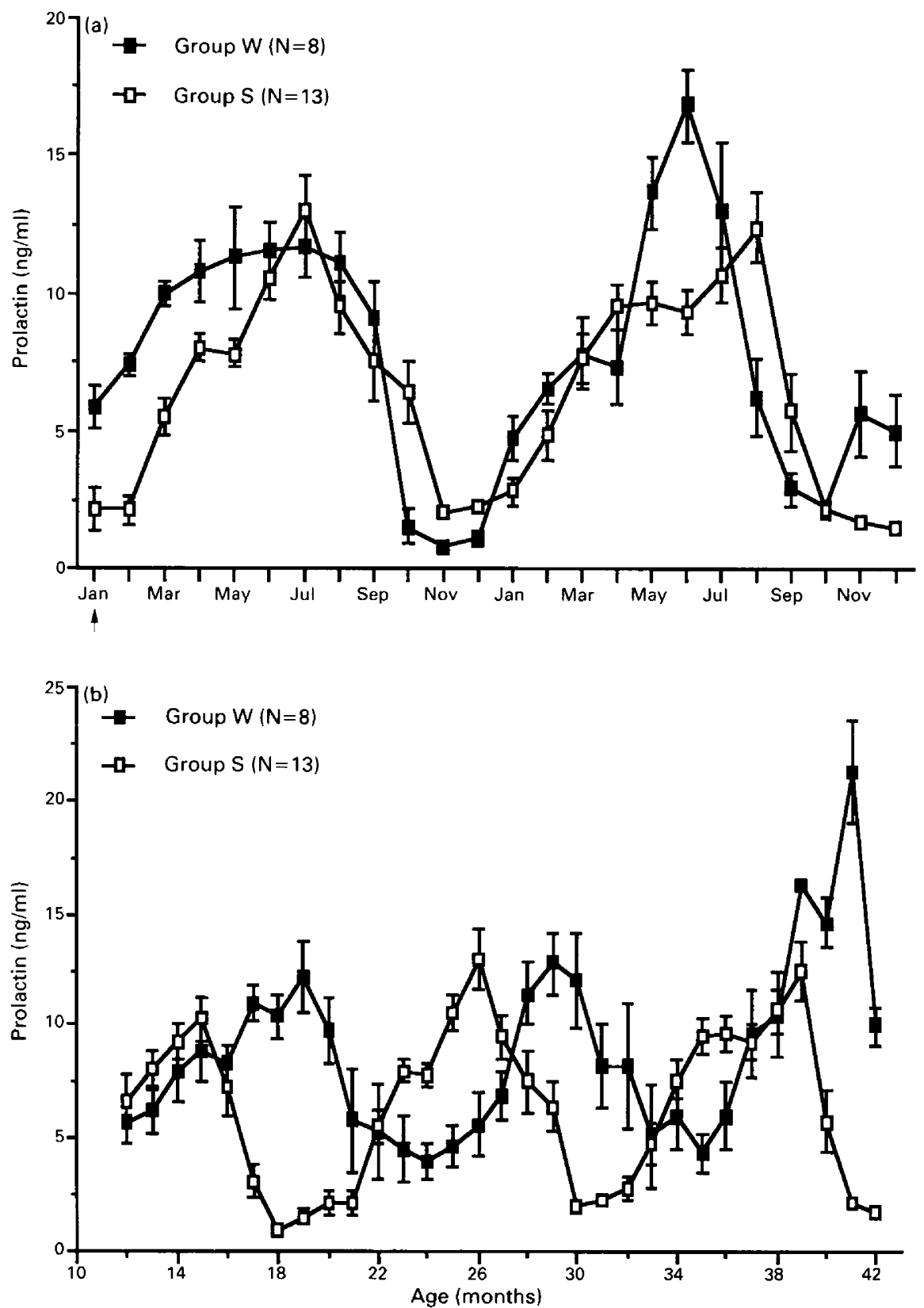

Fig. 3. Developmental changes in serum prolactin concentrations (mean \pm s.e.m.) for females in Groups W and $\mathbf{S}$ when data are aligned to age (b) and month of the year (a). Group W females were $\sim 24$ months of age while Group $S$ females were $\sim 20$ months of age indicated by the arrow in January in (a).

alone were the only important factor. These data are comparable to those reported for sheep in that fall-born lambs also ovulate during the normal fall breeding season but at an older than expected age (Foster, 1981).

Based on colony parturition records, about $20 \%$ of spring-born females are impregnated during the fall months of their 3rd year (Wilson et al., 1984), and, as reported earlier (Wilson et al., 1986), 
this is also the observed rate when ovulations, based on serum progesterone concentrations, are monitored. In contrast, $75 \%$ of the winter-born females in the present study ovulated during their 3 rd year, significantly more than would be expected of spring-born females. These results indicate that these females enter the breeding season at an older developmental age (relative to menarche) and are therefore more likely to ovulate during the environmentally-circumscribed period. This is further supported by the observation that the date of first ovulation for these early ovulating Group W females was significantly earlier than that of the early ovulating Group $\mathrm{S}$ females. In contrast, there was no difference in the date of first ovulation between the later ovulating females in Groups W and S: by this age females in both groups had attained the ability to ovulate, but were limited by the environment until the breeding months had begun. Females in both groups showed the initial sign (i.e. menarche) of impending maturation at similar chronological ages, but since this occurred earlier in the year (i.e. summer) for Group W females, these animals had more time to mature before and within the normal breeding season. Indeed, the 2 Group W females that did not ovulate until 45 months experienced menarche later in the year than did the other Group W females (mid-October compared with August). These data are consistent with the observation that an early age at menarche for Group S females increases the likelihood that first ovulation will occur at $2 \frac{1}{2}$ years (Wilson et al., 1986). Conversely, a late menarche typically indicates that first ovulation will be delayed until the next autumn at 43 months of age. Although a similar analysis of rhesus monkeys raised indoors under conditions devoid of seasonal cues revealed that females born in the spring or summer experienced menarche at a later age than did females born in the fall or winter, the occurrence of menarche was distributed throughout all months of the year (Terasawa et al., 1983). Interestingly, $80 \%$ of these females raised indoors ovulated between October and January but since month of birth was not reported for these females it is not known how this variable affected month of first ovulation in these animals (Terasawa et al., 1983).

It therefore seems likely that the delay in first ovulation until a later age for Group $\mathrm{W}$ monkeys is due to these females maturing at a time of the year in which LH secretion is seasonally suppressed. This mechanism accounts for the delay in first ovulation in fall-born lambs to a later age but an appropriate time of year (Foster, 1981). A similar mechanism would operate for those Group S females which exhibit menarche late in the breeding season and in which first ovulation is delayed for 10-12 months. In these animals, enhanced oestradiol negative feedback inhibition on LH secretion becomes operative as these post-menarchial females enter the spring months (Wilson et al., 1986). Concentrations of LH are maximally suppressed by low values of oestradiol in these females until the next autumn. Although a Group W female may be capable of secreting LH to drive ovarian function at 31 or 43 months, this would occur at a time of the year in which environmentally induced oestradiol negative feedback is maximal. Although a non-gonadal restraint mechanism accounts for low concentrations of LH during prepuberty (Terasawa et al., 1984; Wilson et al., 1986), the later stages of maturation are characterized by a diminution of oestradiol negative feedback in inhibition of LH (Rapsisarda et al., 1983; Wilson et al., 1986; Winter et al., 1987). Once females progess through this later stage of puberty and are exposed to the inhibitory spring and summer months. LH values become maximally suppressed by the seasonal induction of oestradiol negative feedback, limiting first ovulation to the autumn months. These data suggest that environmental cues override the endogenous regulation of puberty to effect seasonal restriction of first ovulation.

A possible confounding factor with the present analysis is the heterogeneity of the subject population. All females remained with their mothers until at least 4 months of age, beyond the age at which nursing no longer provides the major source of nutrition. Nevertheless, it is possible that females raised in close proximity to their mothers would show differential rates of development. However, it would be difficult to suggest how this might account for the discrete seasonal restriction of first ovulation for females in Groups $\mathrm{S}$ and W. It is unlikely that the heterogeneity of the subjects accounted for the seasonal restriction of first ovulation for a number of reasons. Weight gain throughout maturation was indistinguishable among groups, indicating that relocation to a new 
facility for most of the Group $\mathrm{W}$ females did not differentially affect growth rate. Furthermore, it must be emphasized that the hypothesis that first ovulation but not menarche would be restricted to the fall or winter months, regardless of origin or month of birth, was supported. If genetic differences existed among the animals to account for the distribution in age at first ovulation (see Fig. 2) rather than seasonal influences, it would be difficult to explain the observation that age at menarche was similar among all animals (see Fig. 1). Our hypothesis that the environment accounted for the seasonal restriction of first ovulation, regardless of month of birth, is supported by the observation that adult rhesus monkeys relocated from the northern hemisphere to the southern hemisphere continue to exhibit ovulations restricted to the fall and winter (Bielert \& Vandenbergh, 1981).

As found in a variety of mammals (Howles et al., 1980; Tucker, 1981; Schanbacher \& Crouse, 1981; Schillo et al., 1983) including rhesus monkeys (Wilson et al., 1985), serum prolactin concentrations varied seasonally in the animals in the present study with high concentrations in the spring and summer and nadirs in fall and winter. Evidence that this pattern is environmentally driven is obtained from the observation that the rhythm was 4-6 months out of phase for the Group W females compared to Group $S$ animals when the data were aligned to age. These data corroborate those from heifers in which prolactin release is related to photoperiod and temperature rather than age (Schillo et al., 1983). The present study could not ascertain whether the prolactin rhythm itself is important or whether it reflects the existence of an underlying neuroendocrine rhythm which restricts first ovulation to the fall months. A seasonal rhythm in prolactin is not evident in seasonally anovulatory adult rhesus monkeys, independent of pregnancy and lactation (Walker et al., 1985), and prolactin does not influence the seasonal response to oestradiol negative feedback on LH in sheep (Webster \& Haresign, 1983). This seasonal rhythm in prolactin during development may not be involved in regulating the tempo of puberty.

In summary, the results clearly indicate that first ovulation is restricted to the short days of autumn and winter in outdoor-housed rhesus monkeys regardless of month of birth. The environmental cue which modulates the tempo of puberty for rhesus monkeys housed in this fashion is not known but, as found in lambs (Yellon \& Foster, 1985), photoperiod may be the critical factor. However, the lamb has first ovulation by $\sim 32$ weeks of age after exposure to long days followed by short days (Yellon \& Foster, 1985). In contrast, the rhesus monkey is exposed to at least $2 \frac{1}{2}$ years of changing photoperiod before first ovulation, and so the photoperiodic requirements for a seasonal effect on first ovulation are not known.

We thank Kathy Chikazawa, Susan Glasco, and Susie Lackey for valuable technical assistance; and L. Wright for editorial assistance. Reagents for the prolactin assay were a gift from the National Hormone and Pituitary Program. All assays were performed in the Yerkes RIA Laboratory. This work was supported by NIH grant HD 16305 and, in part, NIH RR00165. The Yerkes Primate Center is fully accredited by the American Association for the Accreditation of Laboratory Animal Care.

\section{References}

Bielert, C. \& Vandenbergh, J.G. (1981) Seasonal influences on births and male skin coloration in rhesus monkeys (Macaca mulatta) in the southern hemisphere. J. Reprod. Fert. 62, 229-233.

Foster, D.L. (1977) Luteinizing hormone and progesterone secretion during sexual maturation of the rhesus monkey: short luteal phases during the initial menstrual cycles. Biol. Reprod. 17, 584-590.

Foster, D.L. (1981) Mechanism for delay of first ovulation in lambs born in the wrong season (fall). Biol. Reprod. 25, 85-92.
Gordon, T.P. (1981) Reproductive behavior in the rhesus monkey: social and endocrine variables. Am. Zool. 21, 185-195.

Howles, C.M., Webster, G.M. \& Haynes, N.B. (1980) The effect of rearing under a long or short photoperiod on testis growth, plasma testosterone and prolactin concentrations, and the development of sexual behavior in rams. $J$. Reprod. Fert. 60, 437-447.

Rapsisarda, J.J., Bergman, K.S., Steiner, R.A. \& Foster, D.L. (1983) Response to estradiol inhibition of tonic luteinizing hormone secretion decreases during 
the final stage of puberty in the rhesus monkey. Endocrinology 112, 1172-1179.

Rawlins, R.G. \& Kessler, M.J. (1985) Climate and seasonal reproduction in the Cayo Santiago macaques. $A m$. $J$. Primatol. 9, 87-99.

Schanbacher, B.D. \& Crouse, J.D. (1981) Photoperiodic regulation of growth: a photosensitive phase during light-dark cycle. Am. J. Physiol. 241, E1-E5.

Schillo, K.K., Hansen, P.J., Kamwanja, L.A., Dierschke, D.J. \& Hauser, E.R. (1983) Influence of season on sexual development in heifers: age at puberty as related to growth and serum concentrations of gonadotropins, prolactin, thyroxine and progesterone. Biol. Reprod. 28, 329-341.

Terasawa, E., Nass, T.E., Yeoamn, R.R., Loose, M.D. \& Schultz, N.J. (1983) Hypothalamic control of puberty in the female rhesus macaque. In Neuroendocrine Aspects of Reproduction, pp. 149-182. Ed. R. L. Norman. Academic Press, New York.

Terasawa, E., Bridson, W.E., Nass, T.E., Noonan, J.J. \& Dierschke, D.J. (1984) Developmental changes in luteinizing hormone secretory pattern in peripubertal female rhesus monkeys: comparisons between gonadally intact and ovariectomized animals. Endocrinology 115, 2233-2240.

Tucker, H.A. (1981) Photoperiodic control of hormones, growth and lactation in cattle. In Environmental Factors in Mammalian Reproduction, pp. 54-73. Eds D. Gilmore \& B. Cook. University Park Press, New York.

Van Horn, R.N. (1980) Seasonal reproductive patterns in primates. Prog. Reprod. Biol. 5, 181-221.

Walker, M.L., Gordon, T.P. \& Wilson, M.E. (1982) Reproductive performance in capture acclimated female rhesus monkeys (Macaca mulatta). J. med. Primatol. 11, 291-302.
Walker, M.L., Wilson, M.E. \& Gordon, T.P. (1984) Endocrine control of the seasonal occurrence of ovulation in rhesus monkeys housed outdoors. Endocrinology 114, 1074-1081.

Walker, M.L., Wilson, M.E., Schwartz, S.M. \& Gordon, T.P. (1985) Influence of prolactin on gonadotropin secretion in postpartum females. Biol. Reprod. 32 (Suppl. 1), 168, Abstr.

Webster, G.M. \& Haresign, W. (1983) Seasonal changes in $\mathrm{LH}$ and prolactin concentrations in ewes of two breeds. J. Reprod. Fert. 67, 465 471.

Wilks, J.W., Hodgen, G.D. \& Ross, G.T. (1979) Endocrine characteristics of ovulatory and anovulatory menstrual cycles in the rhesus monkey. In Human Ovulation, pp. 205-218. Ed. E. S. E. Hafez. Elsevier/ North Holland, Amsterdam.

Wilson, M.E., Gordon, T.P., Blank, M.S. \& Collins, D.C. (1984) Timing of sexual maturity in female rhesus monkeys (Macaca mulatta) housed outdoors. $J$. Reprod. Fert. 70, 625-633.

Wilson, M.E., Walker, M.L., Schwartz, S.M. \& Gordon, T.P. (1985) Gonadal status influences developmental patterns of serum prolactin in female rhesus monkeys housed outdoors. Endocrinology 116, 640-645.

Wilson, M.E., Gordon, T.P. \& Collins, D.C. (1986) Ontogeny of luteinizing hormone secretion and first ovulation in seasonal breeding rhesus monkeys. Endocrinology 118, 293-301.

Winter, J.S.D., Ellsworth, L., Fuller, G., Hobson, W.C., Reyes, F.I. \& Faiman, C. (1987) The role of gonadal steroids in feedback regulation of gonadotropin secretion at different stages of primate development. Acta endocr., Copenh. 114, 257-268.

Yellon, S.M. \& Foster, D.L. (1985) Alternate photoperiods time puberty in the female lamb. Endocrinology 116, 2090-2097.

Received 12 July 1988 